\title{
Erratum zu: Neue Systeme zur Antikörperherstellung
}

\author{
MARLITT STECH ${ }^{1}$, OLGA NIKOLAEVA ${ }^{1,2}$, STEFAN KUBICK ${ }^{1}$ \\ ${ }^{1}$ ABTEILUNG ZELLFREIE UND ZELLBASIERTE BIOPRODUKTION, FRAUNHOFER-INSTITUT FÜR ZELLTHERAPIE UND IMMUNOLOGIE \\ (IZI), INSTITUTSTEIL BIOANALYTIK UND BIOPROZESSE (IZI-BB), POTSDAM \\ ${ }^{2}$ INSTITUT FÜR BIOTECHNOLOGIE, MEDIZINISCHE BIOTECHNOLOGIE, TU BERLIN
}

DOI: $10.1007 / \mathrm{s} 12268-017-0862-9$

(C) Der/die Autor(en)

Online veröffentlicht am: 30. September 2017

(C) Springer-Verlag GmbH

DOI: $10.1007 / \mathrm{s} 12268-017-0851-\mathrm{Z}$

Der Artikel „Neue Systeme zur Antikörperherstellung“, von Marlitt Stech, Olga Nikolaeva und Stefan Kubick, wurde ursprünglich am 30. September 2017 ohne Open Access online auf SpringerLink publiziert. Die Autoren haben sich jedoch nachträglich für eine Open Access-Veröffentlichung entschieden.
Das Copyright des Artikels wurde deshalb im November 2017 in (C) Der/die Autor(en) 2017 geändert und der Artikel wird nun unter der Creative Commons Namensnennung 4.0 International Lizenz (http://creativecommons.org/licenses/by/4.0/deed.de) veröffentlicht, welche die Nutzung, Vervielfältigung, Bearbeitung, Verbreitung und Wiedergabe in jeglichem Medium und Format erlaubt, sofern Sie den/die ursprünglichen Autor(en) und die Quelle ordnungsgemäß nennen, einen Link zur Creative Commons Lizenz beifügen und angeben, ob Änderungen vorgenommen wurden.
Die Online-Version des Original-Artikels finden Sie unter: https://link.springer.com/ article/10.1007/s12268-017-0851-z.

Korrespondenzadresse:

Dr. Stefan Kubick

Fraunhofer-Institut für Zelltherapie und Immunologie (IZI)

Institutsteil Bioanalytik und Bioprozesse (IZI-BB) Am Mühlenberg 13

D-14476 Potsdam

Tel.: 0331-58187306

Fax: 0331-58187199

stefan.kubick@izi-bb.fraunhofer.de 